\title{
Minocycline Hydrochloride
}

National Cancer Institute

\section{Source}

National Cancer Institute. Minocycline Hydrochloride. NCI Thesaurus. Code C47622.

The hydrochloride salt of minocycline, a broad spectrum long-acting derivative of the antibiotic tetracycline, with antibacterial and anti-inflammatory activities. Minocycline binds to the bacterial 30 S ribosomal subunit and interferes with the binding of tRNA to the ribosomal complex, thereby inhibiting protein translation in bacteria. In addition, minocycline inhibits the inflammatory enzyme 5-lipoxygenase (5LOX) and may impede T cell-microg lia interactions; both activities may contribute to minocycline's neuroprotective effects. 5LOX catalyzes the synthesis of inflammatory mediators such as prostaglandins and leukotrienes. 